Recebido em 12/2011. Aceito para publicação em 10/2012.

\title{
PARTICIPAÇÃO POPULAR DOS MORADORES DE RUA NA GESTÃo PÚBLICA DO MUNICÍPIO DE PORTO ALEGRE, RS
}

\section{POPULAR PARTICIPATION BY HOMELESS RESIDENTS IN PUBLIC MANAGEMENT IN THE MUNICIPAL OF PORTO ALEGRE, RS}

\author{
Cristiane Martins Lima ${ }^{1}$ \\ José Oswaldo Soares de Oliveira²
}

RESUMO: Este artigo tem como tema a trajetória de um grupo de moradores de rua do município de Porto Alegre, RS, que, contrariando as tendências, instituíram o Fórum da População Adulta em Situação de Rua com o objetivo de inserir suas demandas sociais no Orçamento Participativo do município. Tendo sido criado a partir da setorização por bairros, este instrumento não considerava a participação de pessoas em movimento como é o caso dos cidadãos sem domicílio. Com o apoio de Organizações Não Governamentais, os integrantes do Fórum atingiram o objetivo, demonstrando que a participação popular está ligada às lutas sociais e representa ampliação de cidadania ainda que limitada, isto é, sem alterar as condições estruturais de trabalho e de vida dessa população.

Palavras-chave: moradores em situação de rua; planejamento participativo; políticas públicas; participação popular; orçamento participativo.

ABSTRACT: This article presents the path of a homeless group, who, unlike the trends, were able to found the Homeless Adult Population Forum in Porto Alegre, RS. The group aimed to introduce their social demands into the Participatory Budget of the municipal. This administrative instrument was created by dividing the city into squares but did not consider those who live on the streets. With the aid of nongovernmental organizations, this group achieved its goal and demonstrated that the popular participation is linked with social battles. This represents the enlargement of citizenship, although still limited, without changing the structural conditions of the homeless' way of working and living.

Keywords: homeless; participatory planning; public policies; popular participation; participatory budget.

\footnotetext{
${ }^{1}$ Mestranda em Planejamento Urbano e Regional - Universidade do Vale do Paraíba - Univap. E-mail: themuca@gmail.com.

2 Doutor em Arquitetura e Urbanismo - Universidade de São Paulo - USP, Professor Assistente da Universidade de Taubaté Unitau, Pesquisador Associado do LAPSI-IP-USP e Professor Titular da Univap. E-mail: jose.oswaldo@uol.com.br.
} 


\section{INTRODUÇÃO}

No Brasil, é crescente o número de pessoas que não possuem domicilio e vivem em situação de rua ${ }^{1}$, todavia constata-se uma ausência de políticas públicas ou uma fragilidade no enfrentamento desse e de outros problemas estruturais presentes nos médios e grandes centros urbanos. Mesmo nos municípios onde há política de inclusão e participação social, as perspectivas dos moradores de rua em participarem das deliberações políticas e institucionais não estão necessariamente garantidas, pois, a estrutura participativa tende a ser impeditiva, uma vez que estabelece regras que tornam seu funcionamento complexo e dificultam o fluxo de informações que garantem o acesso ao processo participativo. Como exemplo, tem-se o Orçamento Participativo (OP), instituído no município de Porto Alegre e estruturado a partir da divisão regional dos bairros, o qual tem como alicerce a população residente em local fixo, distinto da realidade, por exemplo, de quem mora nas ruas.

O cotidiano da pessoa em situação de rua não possibilita uma articulação mais complexa entre seus membros, e essa dificuldade em se articular no plano das políticas públicas e se organizar coletivamente dificulta ainda mais as suas chances de inclusão no plano institucional e, por consequência, a possibilidade de melhoria na sua condição social. No entanto, existem exceções e entre elas destaca-se o movimento desencadeado no Município de Porto Alegre, por um grupo de moradores de rua que se organizaram e instituíram um Fórum denominado Fórum da População Adulta em Situação de Rua (FPASR). Por meio desse movimento, seus integrantes inseriram-se no plano institucional, no caso o OP. O presente artigo tem como escopo demonstrar que os processos de participação popular podem ocorrer de diversas formas, inclusive fora do plano institucional. Porém, em todas elas o incentivo à participação torna-se peça fundamental na construção e exercício da cidadania, visto que estimulam a inserção social e a busca constante por melhores condições de vida, a exemplo do que ocorreu com os moradores de rua, no município de Porto Alegre, RS.

Os levantamentos das informações contidas no presente texto estão pautados em dados estatísticos fornecidos pelo relatório do Cadastro de Crianças, Adolescentes e Adultos em Situação de Rua e Estudo do Mundo da População Adulta em Situação de Rua de Porto Alegre, RS, realizado em 2007 pelo Instituto de Filosofia e Ciências Humanas - Laboratório de Observação Social, da Universidade Federal do Rio Grande do Sul, o Sumário Executivo da Pesquisa Nacional sobre a População em Situação de Rua, realizado pelo Meta Instituto de Pesquisa de Opinião, na Política Nacional para Inclusão Social da População em Situação de Rua, instituída pelo DecretoLei $n^{\circ} \mathbf{7 . 0 5 3}$, de 23 de dezembro de 2009, e nos dados empíricos, vivenciados em trabalho de campo, no município de Porto Alegre. Destacam-se, dentre outras bibliografias, as de Mattos e Ferreira (2004), Mendes et al. (2004) e Moura (2007).

\footnotetext{
${ }^{1}$ A expressão população em situação de rua é utilizada para definir uma situação temporária vivenciada pela pessoa que está morando na rua, uma vez que, essas pessoas almejam mudar essa situação e retornar ao convívio social, deixando, assim, de morar nas ruas.
} 


\section{A POPULAÇÃO EM SITUAÇÃO DE RUA E OS ESTIGMAS SOCIAIS.}

Alguns conceitos são fundamentais para se compreender a produção dos valores desenvolvidos pela pessoa em situação de rua. Segundo Ghirardi et al. (2005, p. 601), essa pessoa passa por um processo de adequação ao espaço público que abarca principalmente a adaptação a essa nova fase de vida, que rompe com todos os conceitos anteriormente vividos por ele. Esse processo divide-se em três momentos distintos: o ficar na rua, estar na rua e ser da rua.

Ao cair na rua o sujeito ainda preserva alguns vínculos com o 'outro lado' que the permite conseguir trabalho, mantendo contatos com alguns colegas e também com alguns parentes. Estabelecendo-se em albergues, pensões e alojamentos, pode-se dizer que, neste primeiro momento, o indivíduo fica na rua, uma vez que ainda preserva uma rede de relações de suporte. Com o passar do tempo, transforma-se a relação com o espaço das ruas em um processo de progressiva identificação com outros sujeitos cujas rotinas the são semelhantes e permite que se estabeleça uma nova rede de relações que vai, aos poucos, substituir as antigas redes sociais [...] A rua e seus moradores tornam-se progressivamente mais importantes como referência para o sujeito e, dessa forma, um novo cotidiano se estrutura a partir desse novo referencial. Pode-se dizer, então, que este sujeito está na rua. A desvinculação gradativa das redes sociais de suporte e a adesão aos códigos das ruas permite uma articulação do cotidiano em torno desta nova realidade. $O$ espaço das ruas se constitui como local de moradia e de trabalho, nesse momento o sujeito passa a ser da rua. (GHIRARDI et al., 2005, p. 601).

Ressalta-se que a identificação e o reconhecimento dessas fases são essenciais para 0 desenvolvimento de políticas públicas que visam à reintegração desse cidadão ao convívio social, pois, quanto maior o tempo de permanência nas ruas, menor a chance de reintegração.

Viver dessa forma estabelece estereótipos que acabam incorporados por essas pessoas de forma involuntária, assim, as representações sociais repercutem na construção de suas identidades, como definem Mattos e Ferreira (2004, p. 50):

A caracterização das pessoas em situação de rua como anormais, carrega em si a comparação com uma 'normalidade' vista como forma legítima de vida na sociedade. Assim o diferente passa a ser objeto de estranhamento e repulsa. A dicotomia 'normal' versus 'anormal' homogeneíza as diferenças com o intuito de 'manter todos na linha', reproduzir uma dada ordem social. Ora, se morar em uma residência fixa, trabalhar formal- 
mente e constituir família são padrões normais, logo sem residência fixa, sem família e trabaIho formal, as pessoas em situação de rua são alvos de investidas ideológicas que acentuam suas 'anormalidades' (MATTOS; FERREIRA, 2004, p. 50).

Desse modo, o morador de rua incorpora, de maneira gradual e negativa, os estigmas sociais que lhe são imputados por meio de ideologias dominantes. Mattos e Ferreira (2004, p. 50-51) demonstram a dicotomia e a origem desses estigmas. Ao referir-se a um morador de rua como anormal, perigoso, sujo, vagabundo e coitadinho, paralelamente se utiliza de um "discurso higienista", nesse caso utilizado para associar a pessoa em situação de rua à sujeira, levantando a questão da "limpeza das ruas". O mesmo ocorre quando se associa essa pessoa ao perigo e à violência, na realidade, associa-se à pobreza que sugere o perigo. Enquanto a figura de um vagabundo está relacionada ao conceito capitalista, pois, se ela não vende sua força de trabalho, se ela não tem um emprego formal com carteira assinada, ela é improdutiva e, por isso, "preguiçosa e/ou vagabunda". Já o termo "coitadinho" é usado para designar uma visão meramente assistencialista e paliativa, que tende a manter o problema. Stoffels (1977, p. 17) expõe que essas pessoas ainda podem ser chamadas de "loucas" devido à perda de identidade que está relacionada ao tempo de permanência na rua. Por fim, Mattos e Ferreira (2004, p. 51) chamam a atenção para as consequências que os estigmas causam às pessoas sem domicílio institucional:

Assim 0 conjunto destas tipificações, suscita nos cidadãos domiciliados ações que trafegam no extremo da total indiferença chegando até à repulsa e à violência física. Percebe-se que todo este discurso serve como pano de fundo para que o sujeito em situação de rua de maneira negativa construa a sua identidade, e talvez por isto, muitas vezes ele acaba por aceitar este destino, o de viver nas ruas (MATTOS; FERREIRA, 2004, p. 51).

Exatamente por não saberem o que fazer, com essas pessoas, a sociedade e o poder público ignoram a relevância da situação desses cidadãos, tendendo à simplificação do problema, como Mendes et al. (2004, p. 49) demonstram a seguir:

[...] um dos traçados fundamentais de nossa formação social é a banalização desta brutal desigualdade. Aceita-se como natural aquilo que deveria causar indignação. Naturalizarse a pobreza como parte de uma fatalidade que, ou sempre existiu ou que, agora, é fruto da globalização. Por conseguinte, seu enfrentamento se dá por meio de políticas focalizadas naqueles grupos identificados segundo determinados parâmetros técnicos, como socialmente mais vulneráveis, conclamando-se o setor privado e a sociedade para participarem de seu atendimento. $O$ debate político se restringe ao alívio da pobreza tomada em termos absolutos e não em termos da desigualdade social vigente. A 
cultura patrimonial brasileira não incorpora padrões básicos e universais de cidadania. Os programas de inclusão social são, de forma geral, circunstanciais e casuísticos, meritocráticos e seletivos (MENDES et al., 2004, p. 49).

Esses fatores devem ser considerados pelo poder público quando da elaboração de políticas voltadas à inclusão social dessas pessoas, porque o período de permanência e vivência nas ruas pode ser decisivo no fator inclusão social para esse indivíduo. Quanto maior o tempo de permanência na rua menores as chances de recuperação socioeconômica dessa pessoa. A aplicação das políticas públicas deve ir além, não basta apenas oferecer moradia e ou albergues é necessário pesquisar o modo de vida $e$ as reais necessidades voltadas ao setor.

Temos como exemplo os projetos que patrocinam a elaboração de jornais por pessoas em situação de rua, como: "O Trecheiro: notícias do povo da rua", produzido em São Paulo², e o Jornal Boca de Rua, produzido no município de Porto Alegre. Ambos os projetos são desenvolvidos com o apoio de Organizações Não Governamentais que buscam, por intermédio desses trabalhos, demonstrar o cotidiano dessas pessoas, sobretudo valorizando suas qualidades e estimulando o exercício de cidadania.

As próximas seções abordarão algumas das principais características do movimento social produzido pela população adulta em situação de rua, do município de Porto Alegre, RS, evidenciando a sua

2 Esse jornal pode ser encontrado no site http://www.rederua.org.br. organização, a construção da sua trajetória participativa, bem como a importância do apoio das organizações não governamentais durante a construção de uma consciência participativa desenvolvida pelo grupo.

\section{CARACTERÍSTICAS DA POPULAÇÃO EM SITUAÇÃO DE RUA DO MUNICÍPIO DE PORTO, RS}

Para elucidar como ocorreu a trajetória participativa dos moradores sem domicílio institucional no município de Porto Alegre, faz-se necessário apresentar algumas características relevantes do município, bem como da população em situação de rua, ora estudada.

O município de Porto Alegre, segundo dados da Fundação de Economia e Estatística (RIO GRANDE DO SUL, 2011), possui uma população de 1.414.104 habitantes. A economia da cidade é gerada pelos setores de serviços, comércio, agrícola e industrial que investe na criação de indústrias de metalurgia e de confecções. $O$ município acumula mais de oitenta prêmios e títulos que o qualificam como uma das melhores cidades brasileiras para se morar. Essas informações remetem à ideia de que Porto Alegre tem alto nível de qualidade de vida, todavia, quase que esconde a realidade social da população de baixa renda e, principalmente, a dos moradores de rua.

Segundo o estudo realizado pelo Laboratório de Observação Social (Labors), da Universidade Federal do Rio Grande do Sul (UFRGS) ${ }^{3}$, sobre a população adulta em

\footnotetext{
3 O relatório apresenta os resultados finais da pesquisa Cadastro de Crianças, Adolescentes e Adultos em Situação de Rua e Estudo do Mundo da População Adulta em Situação de Rua de Porto Alegre, RS, realizadas entre o segundo semestre de 2007 e o primeiro semestre de 2008 .
} 
situação de Rua, de Porto Alegre, o número total de moradores de rua, no município, é de 1.203 pessoas, sendo que $81,8 \%$ desse total são do sexo masculino e $71,8 \%$ deles têm idade até 44 anos. Constatou-se, também, que $52 \%$ da população pesquisada nasceram no município de Porto Alegre ou na Região Metropolitana do Estado (GEHLEN; SCHUCH, 2008).

Durante a elaboração da pesquisa, foram coletados dados relativos ao cotidiano dessas pessoas para, posteriormente, traçar o perfil desse morador. Assim sendo, uma das perguntas realizadas relacionava-se à razão da ida dessas pessoas para as ruas e a resposta obtida foi: como primeira razão da ida para as ruas: com $41,1 \%$, a ruptura com os vínculos familiares; depois, como segunda razão: com $22,8 \%$, a falta de condições materiais e financeiras, entre essas, $16,3 \%$ alegam o desemprego como causa, enquanto, apenas $6 \%$, a perda de moradia. E em terceiro lugar: com 12,1\%, aparece a dependência do álcool e das drogas como motivo que impulsionou a ida definitiva para a rua.

Outro item que merece destaque é o relacionado à obtenção de renda pelo morador de rua, entre os entrevistados: $22,9 \%$ alegaram obter renda por meio da coleta e venda de material reciclável, enquanto $12,3 \%$, por intermédio da guarda e lavagem de carros. Assim sendo, 29,1\% dos entre-vistados apresentam um ganho mensal de até meio salário mínimo, enquanto, apenas $15 \%$ dos entrevistados sobrevivem por meio de esmolas (GEHLEN; SCHUCH, 2008).

De acordo com os dados obtidos pela pesquisa realizada pelo Labors, os moradores de rua do município de Porto Alegre, RS, sustentam-se, prioritariamente, por meio de trabalhos informais, por exemplo, por meio da coleta de material reciclável ou da vigilância de veículos nas ruas. De tal modo, que apenas uma pequena parcela é improdutiva e sobrevive de esmolas.

Isso demonstra a importância de se elaborar projetos sociais que priorizem a participação popular e a difusão das informações obtidas para que essas informações venham a agregar e valorizar as atividades econômicas e sociais exercidas por essa população.

\subsection{Projetos sociais direcionados à pessoa em situação de rua}

Neste item, ressalta-se a importância da atuação de organizações não governamentais e de instituições que desenvolvem projetos voltados à realidade dessa população. Esses projetos têm como finalidade estimular e desenvolver o exercício de cidadania junto à pessoa em situação de rua, visando a reverter essa situação.

Em meados de 1991, um morador de rua chamado Luís Antonio de Almeida Flores $^{4}$, mais conhecido como Lula, instituiu um movimento popular chamado Movimento dos Direitos dos Moradores de Rua (MDM de rua). Esse movimento visava a organizar e estimular os moradores de rua a participarem de encontros semanais para debaterem os principais problemas enfrentados no seu cotidiano, com intuito de solucioná-los de maneira coletiva e participativa. Originou-se no albergue municipal Abrivivência, atualmente chamado

\footnotetext{
${ }^{4}$ Esses dados foram retirados do texto "Resgate Histórico da organização dos moradores de rua de Porto Alegre" elaborado por moradores de rua e publicado no site: http://www.ongcidade.org/site/arquivos/noticias/ForumMorado resRuaresgatehistorico49da5776ecdbb.pdf.
} 
de Abrigo Marlene, o qual apoiou o projeto.

Em 2001, o MDM de rua teve sua principal proposta, a construção de um galpão para reciclagem, atendida pelo poder público, que foi aprovado no OP. Esse galpão de reciclagem atendeu as 36 famílias de moradores de rua que participaram do movimento. No entanto, após esse fato, o movimento desarticulou-se, perdeu forças e não conseguiu se manter.

Anos mais tarde, a partir de uma articulação idealizada por membros de uma organização não governamental (ONG ALICE), ocorreu o encontro de antigos membros do MDM com outros moradores em situação de rua que possuíam as mesmas ideias. Dessa união, nasceu o Fórum da População Adulta em Situação de Rua. Esse movimento tem como objetivo conscientizar seus integrantes acerca das questões sociais que abarcam a situação de rua, bem como da importância dos movimentos participativos desencadeados naquele município.

A população em situação de rua possui expressão cultural própria, criada a partir da sua vivência cotidiana no território urbano. Essa expressão cultural manifestase de diversas formas, entre elas, no artesanato, na música (Rap ou Hip-hop) e literatura, como, por exemplo, os artigos publicados em Jornais não vinculados à mídia predominante. O Boca de Rua é um jornal que dá voz ao povo de rua e contribui na superação das barreiras sociais, por valorizar seus problemas, sua ideologia e seu modo de se expressar.

Observa-se que muitos dos projetos patrocinados pela ONG contribuem na construção da identidade dessas pessoas.
Tem-se o exemplo da ONG ALICE ${ }^{5}$, que coordena a edição do Jornal Boca de Rua, editado na cidade de Porto Alegre, RS. Esse Jornal propicia o intercâmbio de informações entre os moradores de rua e a sociedade, bem como visa a manter uma consciência política e crítica dentro do grupo, salientando a percepção da cidade.

O Jornal funciona como um canal de comunicação e procura dar voz aos que não têm representação na mídia dominante, oferecendo a oportunidade de produzir um jornal, com edição trimestral.

Os participantes escolhem o tema a ser desenvolvido, gravam e/ou escrevem os textos que serão publicados, e são responsáveis pelas imagens, fotografias ou desenhos que ilustram o jornal. Porém a parte técnica relativa à impressão fica sob a responsabilidade da equipe multidisciplinar de profissionais, contratados pela ONG ALICE. Todo o processo de desenvolvimento da matéria contribui para 0 resgate da autoestima desses cidadãos.

O projeto ainda propicia ao participante uma fonte de renda complementar, pois cada participante do projeto recebe, semanalmente, 20 exemplares do Jornal, os quais são identificados com o seu nome, e por eles vendidos nas ruas de Porto Alegre, ao custo de $R \$ 1,00$ (um real) por exemplar. A renda obtida com a venda do jornal é revertida ao vendedor.

A ONG ainda fornece uma bolsaauxílio aos pais das crianças que participam da elaboração de um encarte que compõe o

\footnotetext{
${ }^{5}$ A Agência Livre para Informação, Cidadania e Educação (ALICE) tem o objetivo de promover a discussão da imprensa, de forma crítica e consciente, e de incentivar projetos sociais e de comunicação.
} 
Jornal principal. Esse encarte recebe 0 nome de "Boquinha".

Nas palavras da população em situação de rua de Porto Alegre: "botar o Boca na rua" significa uma maneira de se defender e expor os seus problemas sociais.

Dessa forma, eles valorizam sua organização social, os problemas em comum, e buscam as possíveis soluções para amenizar as dificuldades cotidianas.

\subsection{A organização social da população em situação e rua e o enfrentamento dos problemas cotidianos}

Em meados do ano de 2007, a Prefeitura Municipal de Porto Alegre, em conjunto com a brigada militar, iniciou uma campanha de remoção dos moradores sem domicílio dos locais públicos, como praças, calçadas e pontes que, posteriormente, foram fechadas com grades e/ou muros. A finalidade dessa campanha, uma ação que exemplifica a visão e a prática higienista, implantada naquele período no município, era de promover a "limpeza" dos espaços públicos na região central da cidade, pois a ocupação das praças e ruas por sem tetos degradava a imagem e interferia na paisagem urbana. Dessa forma, a prefeitura, em conjunto com a Brigada Militar, promoveu o fechamento das bases das pontes com grades e ou muros, e proibiu os moradores de retornarem ao local. Destacase que essa prática não veio associada a nenhum programa ou projeto de encaminhamento social.

Diante desse ato de discriminação e exclusão social, os integrantes do Jornal Boca de Rua abordaram o tema na edição de março de 2007 e expressaram com clareza sua indignação:
A Prefeitura mandou fechar as pontes em Porto Alegre. Os que viviam nestes locais foram para as praças ao redor. De que adianta sair debaixo das pontes e ficar na rua igual? A pressão também está grande com as pessoas que dormem embaixo das marquises. Jogam água nos moradores de rua para eles saírem. Nas praças, tiram deles as poucas coisas que têm, e ainda apanham. A Prefeitura arruma as ruas, mas albergue, que é bom, não faz mais. Tinha que ter mais Casas de Convivências, para a pessoa ter onde ficar durante o dia. As pontes não são melhores do que os abrigos, e nem tem vagas nos abrigos. As que têm são insuficientes (CORDEIRO et al., 2007, p. 2).

O preconceito e a discriminação são uma constante na vida dessas pessoas e podem ser observados em diversas áreas, inclusive na saúde pública. Essa discriminação levou um grupo de moradores de rua e portadores do vírus HIV, do município de Porto Alegre, a procurar o Grupo de Apoio de Prevenção a AIDS para reivindicar tratamento. Esses moradores encontraram apoio nessa instituição e com estímulo puderam fundar o grupo Realidade de Rua e o projeto Hip-Hop Saúde.

Foi por inermédio da música que eles descobriram as ferramentas necessárias para denunciar a situação de exclusão em que viviam. As letras das músicas identificam essa temática: "Que o incentivo pode ajudar alguém a se resgatar / Levar à sociedade a compreensão de que somos todos 
iguais / Não é por que vivemos nas ruas / Que somos marginais" (BOFF, 2007, p. 5).

Além do apoio médico e psicológico, esse projeto propiciou aos integrantes do grupo a chance de exporem seu cotidiano por meio da música e de obterem uma outra fonte de renda, pois o grupo realidade de Rua passou a se apresentar em bares noturnos, no centro da cidade, em troca de cachê.

Constata-se que o movimento da população socialmente excluída possui um grau de coesão e seriedade que possibilita a formação de uma intensa rede social, quando estimulado. A cada encontro, essa população busca novas alternativas para se expressar e, com isso, cria-se uma identidade coletiva e participativa.

Assim Moura (2007, p. 209) acredita que:

Embora a complexidade e as
desigualdades sociais sejam
barreiras inevitáveis, importa
enfatizar que na prática
desenvolvida por estas várias
experiências surgem ações e
relações que vão contra a
histórica tradição patronal,
clientelista, excludente e
limitadora do sistema político
brasileiro (MOURA, 2007, p.
209).

\subsection{O Fórum da População Adulta em Situação de Rua e a participação popular}

Nesta sessão, objetiva-se demonstrar a história da formação do Fórum e os métodos de participação social que foram utilizados por seus integrantes para a inserção do grupo no plano institucional de participação.

Como salientado anteriormente, a estrutura do OP do município de Porto Alegre, RS, é complexa e obedece a uma dinâmica específica que regulamenta todo o processo, essa dinâmica é baseada no ciclo de participação social. Portanto, para entender como o processo se desenvolve, torna-se indispensável a obtenção de informações a respeito desse ciclo.

Assim sendo, alguns integrantes do Fórum buscaram, junto à ONG Cidade $^{6}$, os elementos necessários para que o grupo pudesse compreender o funcionamento desse ciclo para, posteriormente, a ele integrar-se.

O objetivo do trabalho iniciado pela ONG Cidade era levar informações, por meio de seminários sobre o funcionamento, dinâmica e organização do OP. Para tanto, os representantes da ONG Cidade se deslocaram e foram ao encontro da população em situação de rua, levando o conhecimento necessário para que esta se estruturasse. Diversos seminários foram realizados, sendo que alguns ocorreram em albergues e outros espaços públicos, como a Sala 10 do mercado municipal.

Ficou a critério dos representantes do Fórum a divulgação do trabalho realizado

${ }^{6}$ A ONG Cidade é uma "Organização Não-Governamental, sem fins lucrativos, laica e autônoma em relação ao Estado e a partidos políticos. Temos como princípios o direito à cidadania e à autonomia dos movimentos populares. Formação para a cidadania, conhecimentos de gestão pública, análise de políticas sociais, pesquisa e socialização de informações para participantes em espaços públicos e de organização comunitária, bem como para as comunidades em geral, constituem os eixos estruturais de nosso trabalho. Buscamos, desta forma, contribuir para o fortalecimento da gestão democrática, sobretudo através do Orçamento Participativo, bem como no fortalecimento das organizações de base comunitária". 
pela ONG, assim, uma parte do grupo se incumbia em elaborar convites, enquanto outros circulavam pelas ruas da cidade, difundindo $o$ projeto $e$ convidando a população a participar das reuniões. Os convites distribuídos continham o cronograma das atividades, bem como informava o local, data, horário das reuniões e o assunto a ser tratado.

Para tornar os encontros mais atrativos, as representantes da ONG Cidade levavam garrafas térmicas com café que era servido aos integrantes do movimento, pois muitos deles chegavam para a reunião carregando todos os seus pertences e enrolados em cobertores, devido ao frio.

Os seminários ministrados pelos membros da ONG Cidade tinham como intuito elucidar e apoiar os integrantes do Fórum, contribuindo para que obtivessem dados suficientes para se inserir no plano institucional por intermédio do OP. As informações foram passadas de maneira simples, mas consistente, pois os dados estavam relacionados ao funcionamento burocrático do processo. A cada seminário ministrado novos dados eram transmitidos, assim os integrantes do Fórum diminuíam a distância entre a população em situação de rua e a gestão participativa.

Nessas reuniões, um dos autores deste artigo obteve vários dados relativos ao cotidiano dos moradores de rua. Deve-se ressaltar que essas informações foram, por vezes, trocadas por lanches e ou cafés, tudo de maneira informal. Essas conversas informais aconteciam em lanchonetes localizadas no mercado municipal ou na Usina do Gasômetro. A troca de informação por lanche é comum, essa foi a maneira encontrada pelos moradores de rua para obterem algum pagamento pelas informa- ções, porque, segundo sua visão, as pésquisas realizadas pelas universidades não acrescentam nada de novo ao seu cotidiano, inclusive esses moradores apelidaram os pesquisadores de "gravatinhas".

Algumas informações obtidas contrariam os dados oficiais, entre elas a mais alarmante relaciona-se ao número total de moradores de rua no município. Integrantes do Fórum estimavam que, no ano de 2007, o número total de moradores sem domicílio institucional daquele município ultrapassava a 4.000 pessoas, enquanto os dados oficiais apontam para um número bem inferior. Outro dado importante é que a grande maioria dessa população é formada por pessoas solteiras que buscam uma capacitação profissional e não almejam casa própria, mas sim casas coletivas ou alternativas, como os Hotéis Populares.

Após todo esse processo, os integrantes do Fórum da População Adulta em Situação de Rua finalmente participaram de uma plenária realizada na Assembleia Municipal, onde apresentaram seus projetos e reivindicaram seus direitos. Houve um número recorde de moradores de rua presentes nessa plenária realizada na região central, aproximadamente 267 integrantes do movimento permaneceram no local até o encerramento da reunião.

Nos meses seguintes, o Fórum se reuniu com representantes de órgãos municipais, entre eles o Departamento Municipal de Habitação (DEMHAB). Nessa ocasião, tiveram a oportunidade de apresentar ideias e sugestões aos técnicos, como, por exemplo, o projeto de remodelação de prédios públicos abandonados e a construção do "Hotel Popular" que garantiria ao morador de rua pernoitar em local seguro e limpo, pelo valor 
de $R \$ 1,00$ (um real) a diária, com direito a café da manhã. Esse projeto visava a manter a dignidade e liberdade de escolha do cidadão que, sem ter família, busca uma alternativa que não os albergues.

3.3.1 O Fórum da população em situação de rua e o Orçamento Participativo, desafios e perspectivas

Após a inserção no Orçamento Participativo, constatou-se que o Fórum da População Adulta em Situação de Rua não pertencia a nenhuma das regiões administrativas do OP. Essa situação foi resolvida considerando que, apesar de não pertencer, oficialmente, a nenhuma região administrativa da cidade, esse grupo ficaria vinculado à região central da cidade disputando suas demandas com os membros de outros grupos que pertenciam ao mesmo setor administrativo.

Apesar dessa disputa, o Fórum ainda conseguiu aprovar alguns projetos por intermédio do Orçamento Participativo, a exemplo ${ }^{7}$ : reforma total e ampliação das vagas do Abrigo Marlene (verba destinada ao projeto $\mathrm{R} \$ 120.000,00$ - ano de aprovação 2007); Reforma parcial do Abrigo Bom Jesus (ano aprovação 2008); projeto casa cidadã / República para moradores de rua (DEMHAB) e 15 unidades habitacionais a serem construídas pela Prefeitura (ano de aprovação 2008); encaminhamento e aprovação de um Plano de investimento (PI) junto ao DEMHAB, em que o departamento se compromete em destinar, obrigatoriamente, 05

\footnotetext{
${ }^{7}$ Fórum da População Adulta em Situação de Rua, Boletim de Mobilização - Março 2009, elaborado por moradores de rua e publicado no site: http://www.ongcidade.org/site/arquivos/noticias/ForumMorado resdeRuaBoletimMar49da56d7253c4.pdf.
}

unidades habitacionais a moradores sem domicílio institucional, em cada loteamento ou condomínio construído, em qualquer região da cidade (ano aprovação - 2008); aprovação do projeto de Lei $n^{\circ} 9.850$ de 27/11/2007 na Câmara de Vereadores, que cria uma Comissão Intersecretarias, visando à implementação dos projetos desenvolvidos para os moradores sem domicílio institucional. Entre outras realizações, também destacam-se: uma parceria estabelecida entre a prefeitura e o restaurante popular na organização da ceia de Natal da população em situação de rua (anos 2006, 2007, 2008); organização de 2 seminários municipais sobre a população adulta sem domicílio institucional, realizados em julho de 2007 e dezembro de 2008; participação em Fóruns municipais e conferências (Saúde, Assistência social, Direitos Humanos, Cidades etc.) e Conselhos Sociais ou de Direitos.

Após essa trajetória de construção participativa, a população em situação de rua representada pelo FPASR prosseguiu e, segundo dados fornecidos pelo Boletim da ONG Cidade $(2010)^{8}$, os representantes desse movimento participaram do Fórum Social Mundial, realizado no município em 2010, onde expuseram sua trajetória e reivindicaram seus direitos.

\section{CONCLUSÃO}

Procurou-se, neste artigo, indicar elementos para descrever os aspectos da trajetória e da luta dos moradores de rua e a sua inserção ao OP do município. Percebeuse que a conquista dos espaços de

\footnotetext{
${ }^{8} \mathrm{~A}$ publicação citada está à disposição no Boletim da Cidade: Ano 13 - no 28 p. 8 - maio 2010, no site da ONG Cidade. Disponível em: http://www.ongcidade.org.
} 
participação popular está interligada às lutas sociais, uma vez que o modelo administrativo incorporado ao município de Porto Alegre contém características que causam impasses impeditivos e dificultam a expressão popular.

\section{REFERÊNCIAS}

BOFF, M. Moradores de rua alijados da saúde, Jornal Correio do Povo, Porto Alegre, 9 de julho, 2007.

BURSZTYN, M. (Org.). No meio da Rua, Nômades, Excluídos e Viradores. Rio de Janeiro: Gramond, 2003.

COSTA, A. P. M. População em situação de rua: contextualização e caracterização. Textos \& Contextos, Porto Alegre, v.4, n. 4, dez. $2005 . \quad$ Disponível em: http://revistaseletronicas.pucrs.br/ojs/index.p hp/fass/article/viewFile/993/773. Acesso em: 15 jun. 2011.

CORDEIRO, A. da S. et al. Fecharam as pontes: e aí? Jornal Boca de Rua, Porto Alegre, mar./abr./maio, 2007. n. 23, p. 2.

FÓRUM DA POPULAÇÃO ADULTA EM SITUAÇÃO DE RUA, 2008, Resgate Histórico da organização dos moradores de rua de Porto Alegre [online], Disponível em: <http://www.ongcidade.org/site/arquivos/noti cias/ForumMoradoresRuaresgatehistorico49 da5776ecdbb.pdf.

FÓRUM DA POPULAÇÃO ADULTA EM SITUAÇÃO DE RUA, 2009/ Boletim de mobilização março 2009 [online], Disponível em:

http://www.ongcidade.org/site/arquivos/notici as/ForumMoradoresdeRuaBoletimMar49da5 6d7253c4.pdf. Acesso em: 25 ago. 2011.

GEHLEN, I.; SCHUCH, P. (coord.). Cadastro de crianças, adolescentes e adultos em situação de rua e estudo do mundo da população adulta em situação de rua de Porto Alegre/RS. Porto Alegre: UFRGS, 2008. 115 p. (Relatório de pesquisa).

GHIRARDI, M. I. G. Vida na rua e Cooperativismo: transitando pela produção de valores. Interface comun. saúde educ., Botucatu, v. 9, n. 18, p. 601-610, set./dez. 2005.

GROSTEIN, M. D. Metrópole e Expansão Urbana a persistência de processos "insustentáveis". São Paulo em Perspectiva, São Paulo, v. 15, n. 1, p. 13-19, mar. 2001.

MATTOS, R. M.; FERREIRA, R. F. Quem vocês pensam que (elas) são? Representações sobre as pessoas em situação de rua. Psicol. Soc., Porto Alegre, v. 16, n. 2, Aug. 2004. Disponível em: http://www.scielo.br/scielo.php?script=sci_art text\&pid=S0102-

$71822004000200007 \&$ Ing=en\&nrm=iso.

Acesso em: 15 fev. 2011.

MENDES, J. M. R. et al. (Org.). As Múltiplas Formas de Exclusão Social. Porto Alegre: EDIPUCRS, 2004.

MOURA, R. R. Compromisso governamental e orçamento participativo: estudo comparativo das experiências em Blumenau e Chapecó, Santa Catarina. Revista Katálysis, Florianópolis, v. 10, n. 2, p. 206214, jul./dez. 2007.

RIO GRANDE DO SUL. Fundação de Economia e Estatística. Projeção Populações residentes segundo os municípios do Rio Grande do Sul, 2012. Disponível em: www.fee.tche.br. Acesso em: 13 out. 2012.

STOFFELS, M. G. Os mendigos na cidade de São Paulo: ensaio de interpretação sociológica. Rio de Janeiro: Paz e Terra, 1977. 